\title{
Scoping review: a relevant methodological approach for knowledge synthesis in Brazil's health literature
}

\author{
Revisão de escopo: uma abordagem metodológica relevante para a síntese de \\ evidências da literatura em saúde no Brasil
}

\begin{abstract}
AUTHOR'S
Valter Cordeiro Barbosa Filho ${ }^{1,2}$ (D)

Andrea C. Tricco $3,4,5$ (D)

1 Federal Institute of Education, Science and

Technology of Ceara, Aracati, Brazil.

2 Post-graduate Program in Collective Health,

Ceara State University, Fortaleza, Brazil

3 Unity Health Toronto: Knowledge Translation

Program, Li Ka Shing Knowledge Institute, St.

Michael's Hospital of Unity Health Toronto,

Toronto, Ontario, Canada.

4 Epidemiology Division, Dalla Lana School

of Public Health and Institute of Health Policy,

Management, and Evaluation, University of

Toronto, Toronto, Ontario, Canada.

5 Queen's Collaboration for Health Care Quality,

Joanna Briggs Institute Centre of Excellence,

Queen's University, Kingston, Ontario, Canada.
\end{abstract}

\section{CORRESPONDING}

Federal Institute of Education, Science and

Technology of Ceara, Aracati Campus.

Rodovia CE-040, Km 137,1 s/n Aeroporto,

Aracati, Ceará, Brazil.

Zip code: $62800-000$

DOI

$10.12820 /$ rbafs. $24 \mathrm{e} 0082$

\section{(cc) BY-NC-SA}

This work is licensed under the Creative Commons Attribution-NonCommercial-ShareAlike 4.0 International License.

\begin{abstract}
A methodologically robust approach to synthesize relevant knowledge in health literature is the scoping review, which is used to answer broader questions (e.g., "What is known about this concept?") and can be used to map evidence for research and practice decision-making. This paper discussed the importance of scoping reviews as a methodological approach for knowledge synthesis in Brazil's health literature. Definitions and methodological steps were discussed. We examined 45 scoping reviews that were published in Brazil's journals or available as thesis or dissertations to discuss their content and methodological characteristics. Recommendations for authors were presented in order to improve the planning, executing and reporting of further scoping reviews in Brazil. This will help Brazilian researchers and health professionals to understand when and how scoping reviews can be helpful for knowledge synthesis on health topics, including for physical activity and health research area.
\end{abstract}

Keywords: Systematic reviews; Knowledge synthesis; Methodology; Evidence-based healthcare; Brazil. RESUMO

Uma abordagem metodologicamente robusta para sintetizar a literatura relevante em saúde é a revisão de escopo, a qual é utilizada para responder questões abrangentes (por exemplo, "O que se conhece sobre um determinado conceito em saúde?") e pode ser utilizada para mapear evidências para a tomada de decisão prática e em pesquisa. Este artigo discutiu a importância de revisôes de escopo como uma abordagem metodológica para sintese de conhecimento da literatura em saúde no Brasil. As definições e as etapas metodológicas foram discutidas. Um sumário das 45 revisôes de escopo que foram publicadas em periódicos brasileiros ou como tesel dissertação foi apresentado para discutir seu conteúdo e suas características metodológicas. Recomendaçôes para os autores foram apresentadas para melhorar o planejamento, execução e descrição de revisöes de escopo a serem realizadas no Brasil. Este estudo pode ajudar pesquisadores e profissionais de saúde brasileiros a compreender quando e como revisóes de escopo podem ser úteis na sintese de evidências, incluindo para o campo de pesquisas em atividade física e saúde.

Palavras-chave: Revisão sistemática; Sintese de conhecimento; Metodologia; Saúde baseada em evidência; Brasil.

\section{Introduction}

"Knowledge synthesis" gained popularity in the 1970's, when the application of evidence-based decision making were stimulated in healthcare and other scientific fields, such as social science, education, and psycho$\log y^{1-4}$. Different terminology and methodological approaches have been used to knowledge synthesis over time; a study on the typology of reviews identified 14 types of reviews ${ }^{5}$ and a scoping review identified 12 unique emerging knowledge synthesis methods ${ }^{6}$. A knowledge synthesis approach in health literature is the systematic review, which consist of a clearly formulated question (based on a specific clinical question) and uses systematic and explicit methods to identify, select, critically appraise, extract and analyze data from relevant research ${ }^{7}$.

A knowledge synthesis method that can be used to answer much broader research questions than systematic reviews (e.g., "What is known about this concept?") is the scoping reviews ${ }^{8}$. For these types of broad questions, scoping reviews can be used to chart the literature on a given topic, identify research gaps, 
and establish future research agendas ${ }^{4}$ In 2005, Arksey and O'Malley ${ }^{9}$ published the first paper outlining the methodological approach for conducting scoping reviews, and the approach has been updated since then ${ }^{2,10,11}$. As well, the amount of published scoping reviews is growing: two overviews of scoping reviews included more than 300 studies $^{1,3}$. The Preferred Reporting Items for Systematic reviews and Meta-Analyses) statement-scoping reviews (PRISMA-ScR) were established in $2018^{8}$ to improve the reporting of scoping reviews. The purpose of this opinion paper is to discuss the relevance of scoping reviews as a methodological approach for knowledge synthesis in Brazil's health literature.

\section{The evolution of the definition and methodological approach for scoping reviews}

The first publication with the definition and methodological approach for a scoping review was presented by Arksey \& O'Malley in $2005^{9}$. The authors reported that scoping reviews "aim to map rapidly the key concepts underpinning a research area and the main sources and types of evidence available". The authors discussed that scoping reviews focus on achieving in-depth and broad results rather than being guided by a highly focused research question. Thus, performing a scoping review is relevant to: 1) examine the extent, range and nature of research activity; 2) determine the value of undertaking a full systematic review; 3) summarize and disseminate research findings; and 4) identify research gaps in the existing literature?

Arksey \& O'Malley ${ }^{9}$ proposed a methodological approach with five steps: 1) identifying the research question; 2) identifying relevant studies; 3) study selection; 4) charting the data; and 5) collating, summarizing and reporting the results. An optional step can be a 'consultation exercise', in order to validate findings from the main scoping review with key stakeholders. Subsequently, Levac et al. ${ }^{10}$ revised the Arksey and O'Malley's approach, with specific recommendations to clarify and enhance each stage, including a checklist of methodological recommendations for the planning and conduct of a scoping review.

Institutions focused on evidence-based practice and healthcare should consider supporting the scoping review method as a relevant and independent approach for knowledge synthesis. In particular, the Cochrane Public Health Group ${ }^{12}$ published a paper entitled
"Scoping the scope of a Cochrane review" describing how scoping reviews can be used to inform the conduct of a systematic review in public health. Furthermore, the Joanna Briggs Institute published a reviewers' manual with a detailed description of the methodological approach for scoping reviews ${ }^{2}$. The manual is currently being updated by the Joanna Briggs Institute to provide further clarity on the conduct of scoping reviews; additional information by personal communication with Dr. Andrea Tricco.

In a later paper, Colquhoun et al. ${ }^{11}$ discussed the lack of consensus on scoping review terminology, definition, methodology, and reporting and how these aspects limit the potential of scoping reviews as a knowledge synthesis approach. The authors recommended the standardization "scoping review" or "scoping study", as well proposed the definition: "a form of knowledge synthesis that addresses an exploratory research question aimed at mapping key concepts, types of evidence, and gaps in research related to a defined area or field by systematically searching, selecting, and synthesizing existing knowledge"11.

Aiming to address the urgent necessity of reporting guidelines for scoping reviews ${ }^{1,3}$, Tricco et al. ${ }^{8}$ published the Preferred Reporting Items for Systematic reviews and Meta-Analyses statement-extension to scoping reviews (PRISMA-ScR). The guideline outlines a minimum set of items to report in a scoping review, with adjustments of original PRISMA items that may not be appropriate for scoping reviews. The checklist includes 20 items and 2 optional items; 5 of the original PRISMA items were removed because they were not appropriate to scoping reviews, such as meta-analysis items and the wording was modifed in order to capture adequate terminology for scoping reviews [risk of bias is optional].

\section{Mapping scoping review studies in Brazil}

To our knowledge, 45 scoping reviews on health topics in journals from which Brazil is the country of publication, or were dissertations and thesis that were defended in Brazil until 2018. They were achieved after a search in five electronic databases (PUBMED, Scielo, Web of Science, Scopus and Lilacs) and Brazilian Electronic Database of Dissertations and Thesis using ("scoping review" OR "scoping overview" or "scoping study" OR "mapping review" OR "mapping overview" OR "mapping study"). The search was performed in 21 January 2019, without limits for publication date 
and language, and using limits for publications in Brazil. An initial search in databases reached in 516 titles potentially eligible. A screening of titles/abstract and full-text reading were performed, based on whether studies addressed health topics, described a methodological approach for scoping reviews and were published in Brazil. One author (VCBF) performed all study selection and data extraction process.

In general, the first scoping review was published in Brazil in 2015 (9 reviews), and an increase of reviews was observed per year (i.e., 15 reviews in 2018). Most of the reviews were published in peer-reviewed journals (33 reviews), but 12 were dissertations or theses. The periodicals with the highest number of published scoping reviews (three reviews each) were Ciência $\xi^{\circ}$ Saúde Coletiva and Revista Latino-Americana de Enfermagem, and one review was published in the Revista Brasileira de Atividade Física E Saúde (Table 1).Scoping reviews addressed different health topics (Figure 1). In general, scoping reviews addressed heath care (24 times) as the context of interest. Several scoping reviews addressed health professionals as a population of interest; mainly studies on nursing professionals (8 times). Several concepts were addressed, mainly, access, management and prevention (5 times each).

Considering methodological aspects of scoping reviews published in Brazil, 17 studies used Arksey and O'Malley ${ }^{9}$ as support reference for methodological approach. Twelve reviews used the Joanna Briggs Institute approach ${ }^{2}$. Most of the reviews (37 reviews) used the scoping reviews as the main research; however, five used as a step for the development of instruments/ manual/ protocol/framework, and three theses/dissertations presented data from scoping reviews followed by original studies (survey/case study).

Most of included reviews (35 reviews) did not consider grey literature (i.e., theses, dissertations, reports, and other types of unpublished studies) in the search/ selection process. Only six reviews presented information on the extraction process (e.g., calibration exercise, number of extractors, how the data were confirmed). For data synthesis, two reviews performed a formal quality appraisal using pre-defined instruments to define the level of methodological quality of the included studies. Data were presented in Tables in 37 reviews, and 19 reviews used figures/charts in thematic/data synthesis.

All 45 scoping reviews were evaluated in order to determine what the goal of the review was. Most of the reviews (41 reviews) examined the nature of the evidence. However, only five reviews identified areas for future systematic reviews.

\section{Recommendations for designing, performing and writing scoping reviews}

There are several types of knowledge synthesis approaches available to authors. ${ }^{5}$ In Brazil, systematic reviews and integrative reviews are the most frequently used type of knowledge synthesis in the health literature; a search in Scielo Brazil on 30 March 2019 using "systematic review", "integrative review" and "scoping review" reached 2081, 549 and 24 titles, respectively. However, the appreciation for scoping reviews in Brazil's health literature is growing (as observed here). The improvements in methodological guidelines ${ }^{2,11}$, the PRISMA-ScR checklist and its inclusion on the EQUATOR (Enhancing the QUAlity and Transparency Of health Research) Network ${ }^{8}$ may help authors to decide when and how to perform scoping reviews as a suitable knowledge synthesis methodology.

The question that authors desire to address is the key for deciding whether or not a scoping review is the appropriate methodological approach. Munn et al. published a paper providing recommendations to authors when choosing between a systematic review or scoping review ${ }^{4}$. Systematic reviews are likely the most valid approach whether authors wish to use the results of their review to answer a clinically meaningful question. However, scoping reviews may be suitable when the identification of certain characteristics/concepts, as well as the body of literature on a given topic ${ }^{2,4,8}$ is of interest. Thus, scoping reviews can be understood as a hypothesis-generating exercise, while systematic reviews can be hypothesis - testing ${ }^{4,13}$. An example for this was the scoping review written by Marques and Miranda ${ }^{14}$, which addressed the question: what is it known about Photovoice at the international and national literature, and its implications of the collaborative method for investigations in the field of Physical Education? Another distinction between scoping and systematic reviews is that scoping reviews provide an overview of the existing evidence, regardless of quality ${ }^{4}$. Different from systematic reviews, scoping reviews provide a map of what evidence has been produced; thus, in general, the quality appraisal of included studies is not congruent with the purpose of scoping reviews ${ }^{2,8}$; as mentioned in PRISMA-ScR checklist, which described that quality appraisal as being not applicable an optional step for some scoping reviews. 
Table 1 - Publications and methodological characteristics of included scoping reviews from Brazil's health literature $(n=45)$.

\begin{tabular}{|c|c|}
\hline Publication/methodological characteristics & $\mathrm{n}(\% \text { of } 45 \text { studies })^{\mathrm{a}}$ \\
\hline \multicolumn{2}{|l|}{ Year } \\
\hline 2015 & $9(20.0)$ \\
\hline 2016 & $8(17.8)$ \\
\hline 2017 & $13(28.9)$ \\
\hline 2018 & $15(33.3)$ \\
\hline \multicolumn{2}{|l|}{ Type of Publication } \\
\hline Journal papers & $33(73.4)$ \\
\hline Dissertations & $10(22.2)$ \\
\hline Thesis & $2(4.4)$ \\
\hline \multicolumn{2}{|l|}{ Research Areas } \\
\hline Public Health & $12(26.7)$ \\
\hline Nursing & $15(33.3)$ \\
\hline Odontology & $6(13.3)$ \\
\hline Psychology & $4(8.9)$ \\
\hline Medicine & $2(4.4)$ \\
\hline Otorhinolaryngology & $2(4.4)$ \\
\hline Pharmacy & $3(6.7)$ \\
\hline Physical Education & $1(2.2)$ \\
\hline \multicolumn{2}{|l|}{ Referential support } \\
\hline Arksey \& O'malley (2005) only & $17(37.8)$ \\
\hline $\begin{array}{l}\text { Arksey \& O'malley (2005) and updated } \\
\text { references }\end{array}$ & $7(15.6)$ \\
\hline Joanna Briggs Institute $(2011,2015)$ & $12(26.6)$ \\
\hline Others & $4(9.9)$ \\
\hline Not reported & $5(11.1)$ \\
\hline \multicolumn{2}{|l|}{ Geographical limits } \\
\hline Brazil only & $8(17.8)$ \\
\hline $\begin{array}{l}\text { Brazil and others countries (Latin- American } \\
\text { countries or Portugal) }\end{array}$ & $3(6.7)$ \\
\hline European countries & $2(4.4)$ \\
\hline Worldwide & $32(71.1)$ \\
\hline \multicolumn{2}{|l|}{ Scoping review as a research approach } \\
\hline Primary research & $37(82.2)$ \\
\hline $\begin{array}{l}\text { Step for the development of instruments/ } \\
\text { manual/protocol/framework }\end{array}$ & $5(11.1)$ \\
\hline Step for an original study (survey/case study) & $3(6.7)$ \\
\hline \multicolumn{2}{|l|}{ Grey literature searched/included? } \\
\hline Yes & $10(22.2)$ \\
\hline No/Unclear & $35(77.8)$ \\
\hline \multicolumn{2}{|l|}{ Selection process flowchart presented? } \\
\hline Yes & $32(71.1)$ \\
\hline No & $13(28.9)$ \\
\hline
\end{tabular}

Continue...

Similarities exist between the conduct of systematic reviews and scoping reviews. For example, including a detailed protocol that outlined the methods for systematically searching, selecting and synthesizing studies, in order to identify and synthesize relevant literature on the question. This is evident because PRISMA-ScR check-

\begin{tabular}{lc}
$\ldots$ continue & \\
\hline Publication/methodological characteristics & $\mathrm{n}(\% \text { of } 45 \text { studies })^{2}$ \\
\hline Data extraction details given? & $31(68.9)$ \\
Yes & $14(31.1)$ \\
No & \\
Data extraction process detailed? & $6(13.3)$ \\
Yes & $39(86.7)$ \\
No & \\
Quality appraisal of included studies? & $2(4.4)$ \\
Yes & $43(95.6)$ \\
No & \\
Data synthesis in tables? & $37(82.2)$ \\
Yes & $8(17.8)$ \\
No & \\
Data synthesis in figures/charts? & $19(42.2)$ \\
Yes & $26(57.8)$ \\
No & \\
Examined the extent, range, and nature of the & \\
evidence? & \\
Yes & $24(11.1)$ \\
No/Unclear & $40(88.9)$ \\
Identified evidence gaps? & \\
Yes & \\
No/Unclear & \\
Reported specific recommendations that could & \\
be used for policy or practice? & \\
Yes & \\
No/Unclear & \\
Reported explicit recommendations that could be & \\
used for future research? & \\
Nes & \\
\hline
\end{tabular}

Scoping reviews were published in Ciência \& Saúde Coletiva, Revista Latino-Americana de Enfermagem, Cadernos de Saúde Pública, Texto \& Contexto - Enfermagem, Revista da Escola de Enfermagem da USP, Brazilian Dental Journal, Brazilian Journal of Otorhinolaryngology, Brazilian Oral Research, Clinics, Cogitare Enfermagem, Estudos de Psicologia, Interface - Comunicação, Saúde, Educação, International Archives of Otorhinolaryngology, Odontoestomatología, Revista Brasileira de Atividade Física \& Saúde, Revista Brasileira de Enfermagem, Revista Brasileira de Medicina do Trabalho, Revista da Associação Médica Brasileira, Revista da Sociedade Brasileira de Medicina Tropical, Revista de Bioética, Revista de Saúde Pública, Revista Gaúcha de Enfermagem, Revista Interdisciplinar da Mobilidade Humana, Revista Odontológica do Brasil-Central, Scientia Medica and Trabalho, Educação e Saúde.

list preserved all items (items 5 to 10 from checklist) on study search and selection, as well the data extraction (called data charting for scoping reviews) process ${ }^{8}$. Thus, a transparent and reproducible protocol should be present, including a detailed description of the eligibility criteria (related to the types of participants, concept, 


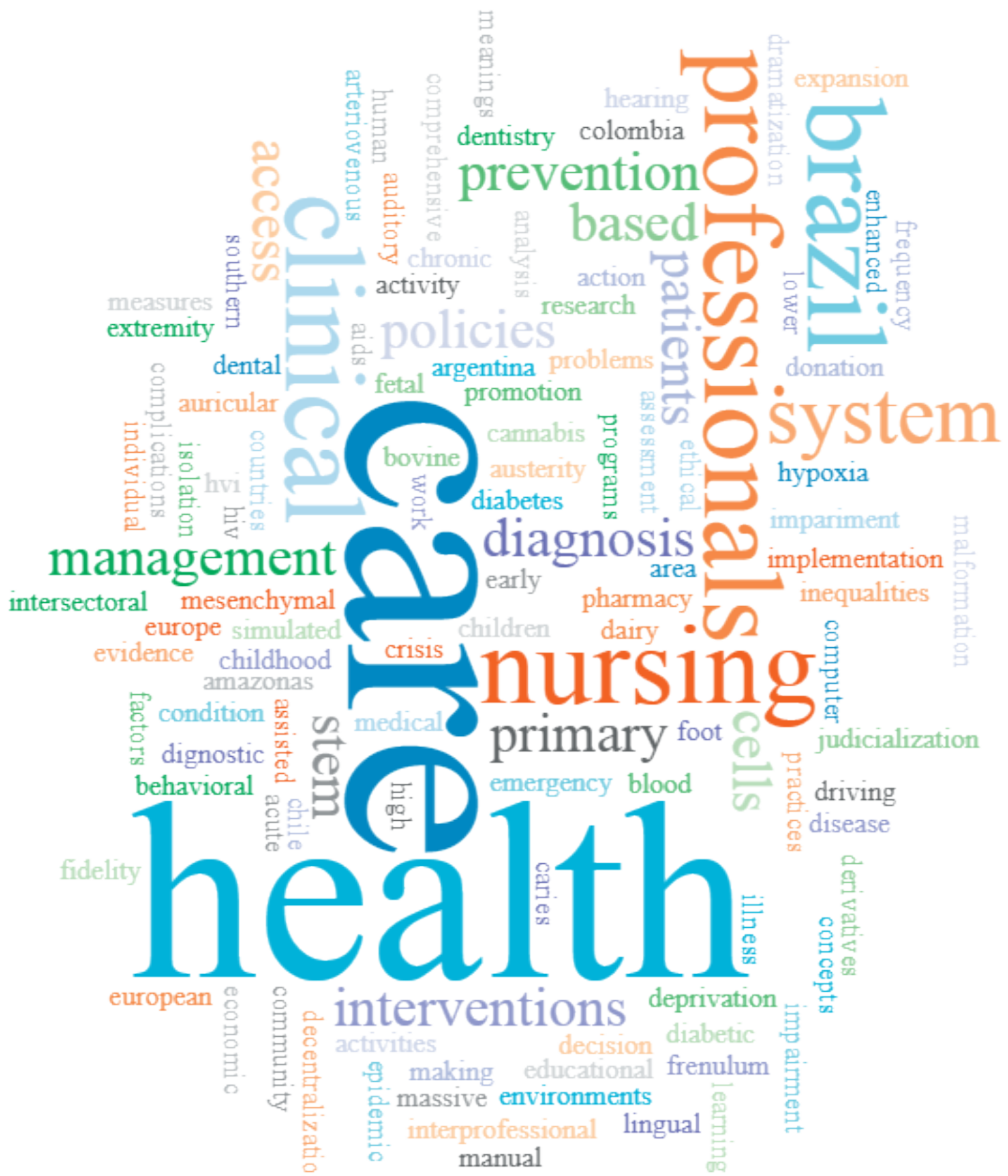

Figure 1 - Word Cloud with themes addressed in scoping reviews published in Brazil (2015-2018).

Word counts: Care $=26 ;$ Health $=24 ;$ Brazil = 10; Clinical = 9; Nursing = 8; Professionals = 8; System $=7 ;$ Access $=5 ;$ Management $=5$; Prevention $=5$

context and study designs), information sources, search strategy, process of selecting studies, and data charting ${ }^{2,8}$.

However, an issue warranting further discussion is what and how data can be synthesized in a scoping review. Based on the assumption that broader topics may include different types of data (quantitative and/ or qualitative) and designs (original and theoretical studies), a comprehensive data charting and synthesis should be considered ${ }^{10,11}$. Authors should ensure that all relevant data were extracted and presented in a structured way in order to identify the types of available evidence and key characteristics, as well as ensure that the results from each research type to answer the topic were attempted ${ }^{2,4,15}$. For this proposes, the production of a schematic illustrative strategy can be helpful, such as evidence maps ${ }^{2,4}$.

Finally, it is urgent to improve the quality of reporting for scoping reviews. Since the PRISMA-ScR 
checklist was published in October 2018 and it was not used so far in scoping reviews published in Brazil, we strongly recommended that authors provide a detailed description of the PRISMA-ScR checklist in order to clarify methodological decisions in scoping reviews.

In conclusion, researchers, health professionals, undergraduate and graduate students interested on health topics may consider the scoping review when a rigorous summary of research is needed to identify the state of knowledge and gaps in the evidence on a broad topic. Scoping reviews are growing since 2015 in Brazil's health literature, but improvements in the methodological quality (e.g., use of a flow chart) and reporting (e.g., data extraction process) aspects should be improved. For example, scoping reviews of topics on physical activity and health may help to understand the bounders and possibilities of the published research and how they can contribute to future research agendas to further research and practice in healthcare.

\section{Conflict of interest}

ACT is the Chair of the Scoping Review Methodology Group for the Joanna Briggs Institute, but the content of the manuscript does not represent an institutional statement.

\section{Authors contributions}

VCBF participated in all stages of the study, including review design, searching and screening of studies, data extraction and draft the first version of the manuscript. ACT participated in review design and contributed substantially to the manuscript. All authors approved the final version of the manuscript.

\section{Funding}

ACT is funded by a Tier 2 Canada Research Chair in Knowledge Synthesis.

\section{References}

1. Tricco AC, Lillie E, Zarin W, O'Brien K, Colquhoun H, Kastner M, et al. A scoping review on the conduct and reporting of scoping reviews. BMC Med Res Methodol. 2016;16(1):15.
2. Joanna Briggs Institute. The Joanna Briggs institute reviewers' manual 2015: Methodology for JBI scoping reviews. Adelaide: The Joanna Briggs Institute; 2015.

3. Pham MT, Rajić A, Greig JD, Sargeant JM, Papadopoulos A, McEwen SA. A scoping review of scoping reviews: advancing the approach and enhancing the consistency. Res Synth Methods. 2014;5(4):371-85.

4. Munn Z, Peters MD, Stern C, Tufanaru C, McArthur A, Aromataris E. Systematic review or scoping review? Guidance for authors when choosing between a systematic or scoping review approach. BMC Med Res Methodol. 2018;18(1):143.

5. Grant MJ, Booth A. A typology of reviews: an analysis of 14 review types and associated methodologies. Health Inf Libr J. 2009;26(2):91-108.

6. Kastner M, Antony J, Soobiah C, Straus SE, Tricco AC. Conceptual recommendations for selecting the most appropriate knowledge synthesis method to answer research questions related to complex evidence. J Clin Epidemiol. 2016;73:43-9.

7. Higgins JPT, Green S (editors). Cochrane Handbook for Systematic Reviews of Interventions Version 5.1.0 [updated March 2011]. The Cochrane Collaboration, 2011. [cited 2018 march 20]. Available at: www.handbook.cochrane.org.

8. Tricco AC, Lillie E, Zarin W, O'Brien KK, Colquhoun $\mathrm{H}$, Levac D, et al. PRISMA extension for scoping reviews (PRISMA-ScR): checklist and explanation. Ann Intern Med. 2018;169(7):467-73.

9. Arksey H, O'Malley L. Scoping studies: towards a methodological framework. Int J Soc Res Methodol. 2005;8(1):19-32.

10. Levac D, Colquhoun H, O'Brien KK. Scoping studies: advancing the methodology. Implement Sci. 2010;5(1):69.

11. Colquhoun HL, Levac D, O’Brien KK, Straus S, Tricco AC, Perrier L, et al. Scoping reviews: time for clarity in definition, methods, and reporting. J Clin Epidemiol. 2014;67(12):1291-4.

12. Armstrong R, Hall BJ, Doyle J, Waters E. 'Scoping the scope' of a cochrane review. J Public Health. 2011;33(1):147-50.

13. Tricco AC, Zarin W, Ghassemi M, Nincic V, Lillie E, Page MJ, et al. Same family, different species: methodological conduct and quality varies according to purpose for five types of knowledge synthesis. J Clin Epidemiol. 2018;96:133-42.

14. Marques B, Miranda ML. Photovoice: implicações do método colaborativo para as pesquisas em Educação Física e Saúde. Rev Bras Ativ Fís Saúde. 2015;20(6):545-58.

15. Nyanchoka L, Tudur-Smith C, Iversen V, Tricco AC, Porcher R. A scoping review describes methods used to identify, prioritize and display gaps in health research. J Clin Epidemiol. 2019;109:99-110.

Receibed: 22/05/2019

Approved: 09/11/2019

Quote this article as:

Barbosa Filho VC, Tricco A. Scoping review: a relevant methodological approach for knowledge synthesis in Brazil's health literature. Rev Bras Ativ Fis Saúde. 2019;24:e0082. DOI: 10.12820/rbafs.24e0082 